\title{
Upper Mississippi River Restoration Program Long Term Resource Monitoring Element-Spatial Data Query Tool
}

The Upper Mississippi River Restoration (UMRR) Program Long Term Resource Monitoring (LTRM) element has been monitoring fish, water quality, and vegetation in six study pools (fig. 1) in the Upper Mississippi River system for approximately 30 years. Geographic locations were recorded for all sampling points. All of this information has been made publicly available by way of data download and visualization tools (https://www.umesc.usgs. gov/ltrm-home.html), but it has not been available to decision makers, scientists, resource managers, and the public by way of an internet-based mapping and query application. Presenting the information in this way is vital to providing decision makers with the information and understanding needed to maintain the Upper Mississippi River system as a viable multiple-use river ecosystem, the primary objective of the UMRR LTRM.

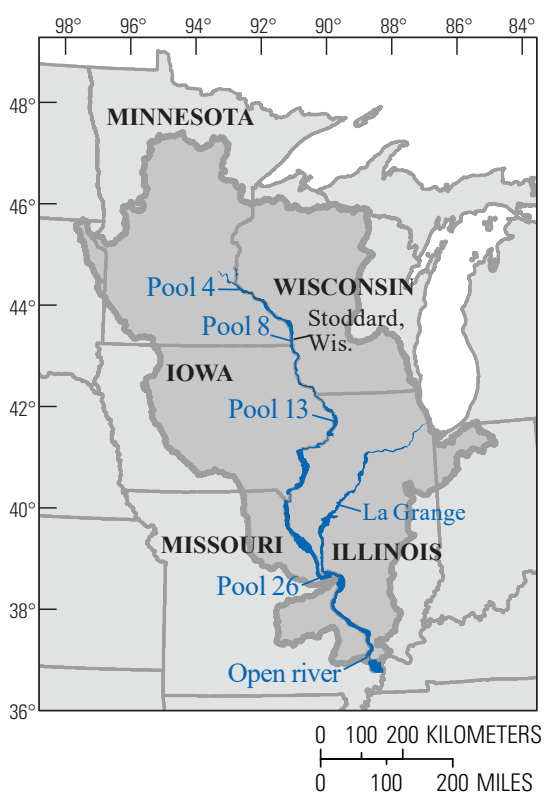

EXPLANATION

Upper Mississippi River Basin Upper Mississippi River System

Figure 1. The Upper Mississippi River Restoration Long Term Resource Monitoring study pools on the Upper Mississippi River system.
Spatial data query tools have been developed that allow the query, display, mapping, and data extraction of the UMRR LTRM element component data by means of an easy-to-use graphical user interface. A separate spatial data query tool application was developed for each study pool within the Upper Mississippi River system (fig. 1) and is accessible as individual links at the bottom of the website located at https://www.umesc.usgs.gov/ltrmp/spatial_ data_query_tool.html. In addition to the UMRR LTRM element component data, the spatial data query tool also contains land cover and bathymetric (water depth) data collected by the UMRR LTRM element.

\section{Using the Spatial Data Query Tool}

The UMRR LTRM element component data can be queried within the "Spatial Data Query Tool" by using the following data query buttons:

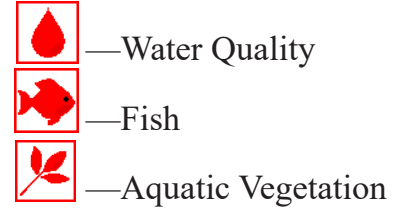

In addition, buttons are available that allow the user to:

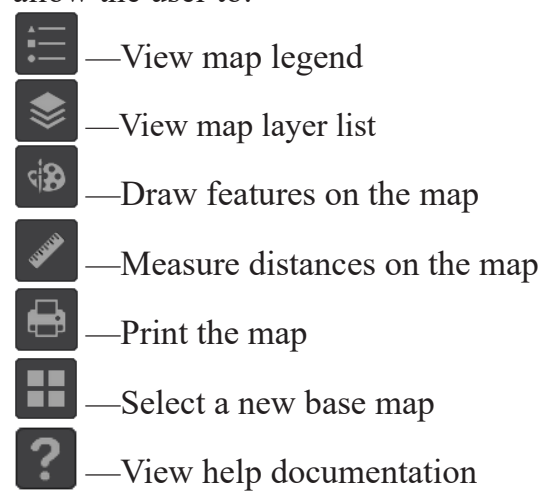

The following sections outline two sample queries using the Water Quality and the Fish query buttons.

\section{Water Quality Sample Query}

In the Upper Mississippi River system, providing over-wintering habitat for fish belonging to the family Centrarchidae (panfish and bass) is the focus of some restoration projects (for example, Johnson and others, 1998). Overwintering refugia for panfish and bass in backwater areas on the Mississippi River need to maintain sufficient oxygen concentrations, adequate temperatures, and also exhibit minimal water flow (Knights and others, 1995).

For the UMRR LTRM water-quality sample query shown in figure 2 , the winter sampling season was selected, the stratum selected was "backwater contiguous," the minimum dissolved oxygen concentration was 5 milligrams per liter, the minimum water temperature was 1 degree Celsius, and the maximum water velocity was 1 meter per second. Research and monitoring suggest that these values represent favorable overwintering conditions for centrarchids.

The highlighted water-quality sample locations on the map (in light blue) denote those areas that conform to the values used in the query. One of the sample locations has been selected, and its tabular attributes are displayed in the popup window on the right.

\section{Fish Sample Query}

The UMRR Habitat Rehabilitation and Enhancement Project (HREP) element has constructed several islands in lower Pool 8 (fig. 1) as part of a multi-phase project to replace those that have disappeared since the construction of the system of locks and dams. Before the lock and dam system was constructed, wave action was not a dominant erosive force in the Mississippi River. Impoundment of the Mississippi River between the locks and dams raised water levels in the impounded areas. This increase in water surface area allowed waves more space to intensify, thereby becoming more destructive as an erosive force, and subsequently the original islands were lost. One of the primary objectives for the second phase of the Pool 8 Islands HREP was to restore habitat where bluegill and largemouth bass overwinter (Johnson and others, 1998). This was accomplished by greatly reducing the amount of water 
and current entering the project area during fall and winter (Janvrin, 2011). This phase of the project was finished in 1999.

For the UMRR LTRM fish sample query shown in figure 3, the sampling dates were restricted to after island construction (January 1, 2000-December 31, 2017), the species was designated as "bluegill," the sampling gear was designated as "DE" for day electrofishing, and the size limits were constrained to select only those sampling points where the largest bluegill were collected. An arbitrary length of at least 2.9 inches (74 millimeters) was used to illustrate a query for large bluegill.

The highlighted fish sample locations on the map (in light blue) denote those areas where bluegill have been sampled that meet the defined parameters. The query tool also allows the user to open, view, and export the tabular data returned by the query (bottom of figure 3).

\section{References}

Janvrin, Jeff, 2011, Pool 8 Islands, Phase I, II and III-Upper Mississippi River Environmental Management Program Habitat Rehabilitation and Enhancement Projects: U.S. Fish and Wildlife Service Upper Mississippi River Wildlife and Fish Refuge news, 8 p., accessed June 25, 2018, at https://www.fws. gov/refuges/news/pdfs/Pool\%208\%20 Islands $\% 20$ Brochure $\% 206 \% 20$ b.pdf.

Johnson, B.L., Knights, B.C., Barko, J.W., Gaugush, R.F., Soballe, D.M., and James, W.F., 1998, Estimating flow rates to optimize winter habitat for centrarchid fish in Mississippi River (USA) backwaters: Regulated Rivers - Research and Management, v. 14, no. 6, p. 499-510.

Knights, B.C., Johnson, B.L., and Sandheinrich, M.B., 1995, Responses of bluegills and black crappies to dissolved oxygen, temperature, and current in backwater lakes of the upper Mississippi River during winter: North American Journal of Fisheries Management, v. 15, no. 2 , p. $390-399$.

\section{By Jason Rohweder}

For additional information contact:

Director, Upper Midwest Environmental Sciences Center

U.S. Geological Survey

2630 Fanta Reed Road

La Crosse, WI 54602

https://www.umesc.usgs.gov/ltrmp/spatial_ data_query_tool.html

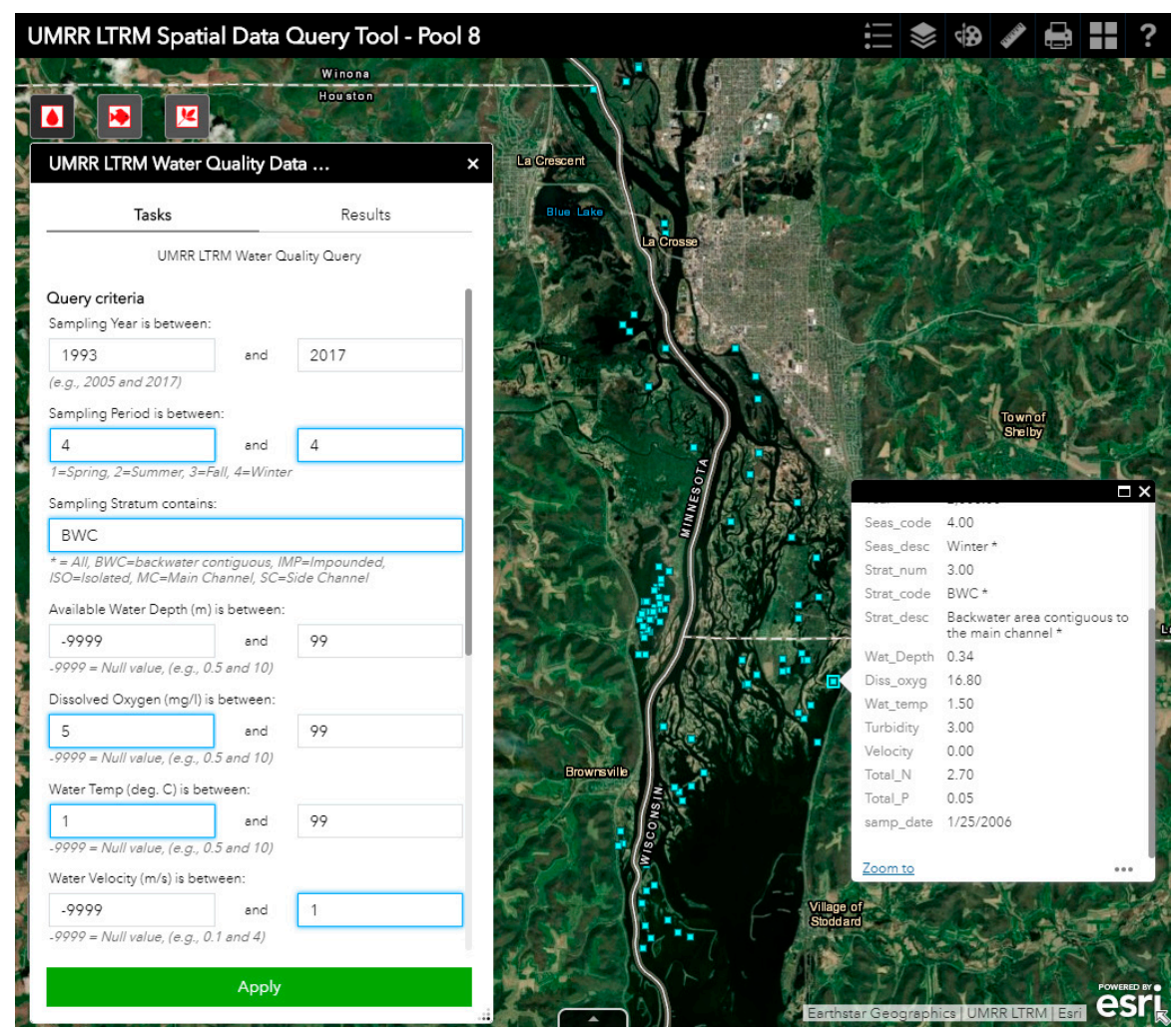

Figure 2. Screenshot showing the spatial data query tool used for capturing water quality results and highlighting sampling locations in backwater areas of Pool 8 where the sampling season was winter, the stratum selected was "BWC" (backwater contiguous), dissolved oxygen concentrations were at least 5 milligrams per liter, and water temperature was at least 1 degree Celsius, and the maximum water velocity was 1 meter per second.

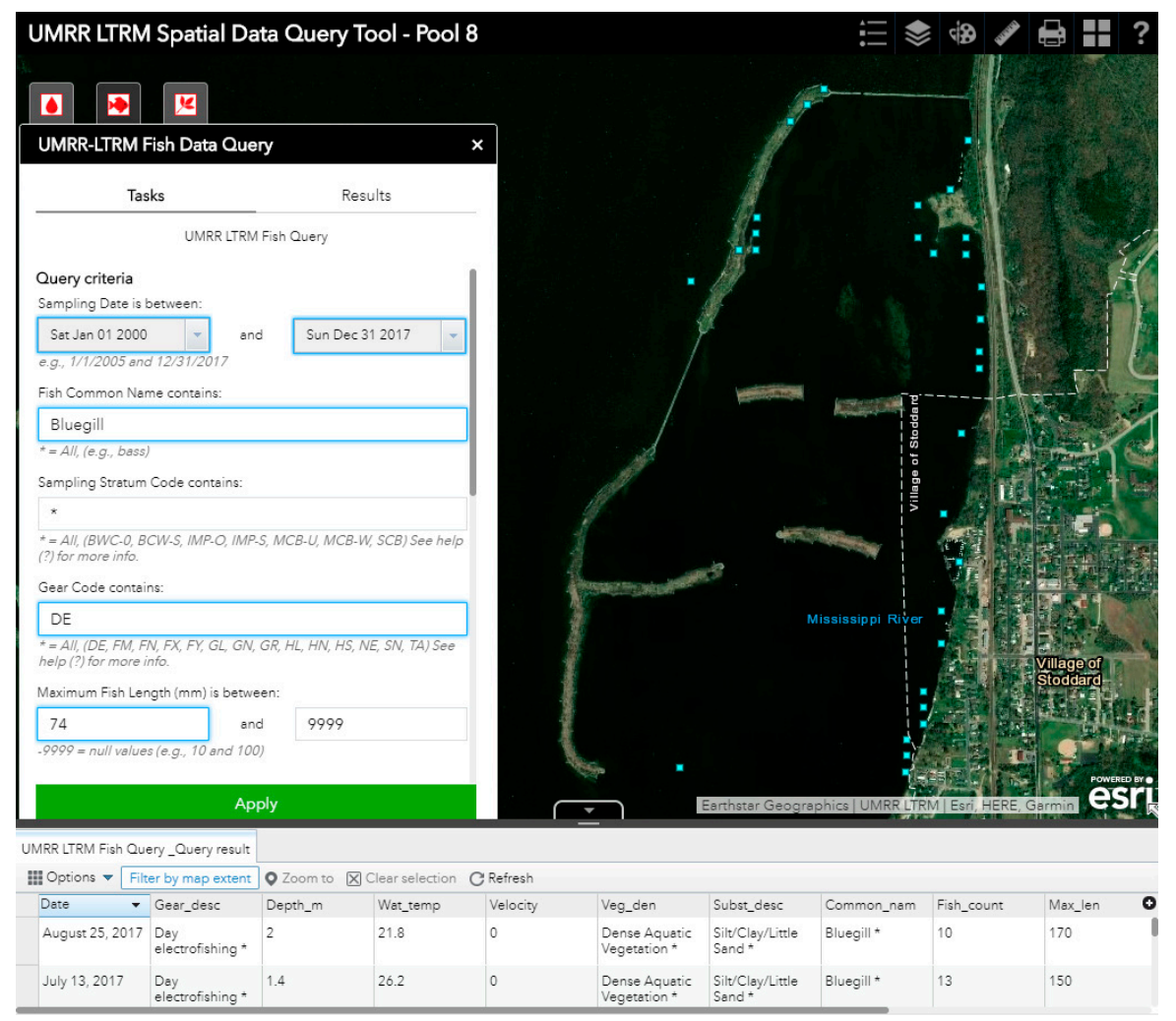

Figure 3. Screenshot showing the results from using the spatial data query tool for fish highlighting sampling locations where bluegill at least 2.9 inches (74 millimeters) long were detected by day electrofishing (DE) after the construction (post 1999) of the Phase II islands near Stoddard, Wisconsin. 